\title{
Noninvasive positive pressure ventilation in acute respiratory failure due to COPD vs other causes: Effectiveness and predictors of failure in a respiratory ICU in North India
}

\author{
Ritesh Agarwal \\ Rajesh Gupta \\ Ashutosh N Aggarwal \\ Dheeraj Gupta \\ Department of Pulmonary Medicine, \\ Postgraduate Institute of Medical \\ Education and Research, Chandigarh, \\ India
}

Correspondence: Ritesh Agarwal Department of Pulmonary Medicine, Postgraduate Institute of Medical Education and Research, Chandigarh I60012, India

Tel +9| 01722756825

Fax +91 01722748215

Email riteshpgi@gmail.com
Objectives: To determine the effectiveness of noninvasive positive pressure ventilation (NIPPV), and the factors predicting failure of NIPPV in acute respiratory failure (ARF) due to chronic obstructive pulmonary disease (COPD) versus other causes of ARF.

Patients and methods: This was a prospective observational study and all patients with ARF requiring NIPPV over a one-and-a-half year period were enrolled in the study. We recorded the etiology of $\mathrm{ARF}$ and prospectively collected the data for heart rate, respiratory rate, arterial blood gases $\left(\mathrm{pH}\right.$, partial pressure of oxygen in the arterial blood $\left[\mathrm{PaO}_{2}\right]$, partial pressure of carbon dioxide in arterial blood $\left[\mathrm{PaCO}_{2}\right]$ ) at baseline, one and four hours. The patients were further classified into two groups based on the etiology of ARF as COPD-ARF and ARF due to other causes. The primary outcome was the need for endotracheal intubation during the intensive care unit (ICU) stay.

Results: During the study period, 248 patients were admitted in the ICU and of these 63 (25.4\%; 24, COPD-ARF, 39, ARF due to other causes; 40 male and 23 female patients; mean [standard deviation] age of 45.7 [16.6] years) patients were initiated on NIPPV. Patients with ARF secondary to COPD were older, had higher APACHE II scores, lower respiratory rates, lower $\mathrm{pH}$ and higher $\mathrm{PaCO}_{2}$ levels compared to other causes of ARF. After one hour there was a significant decrease in respiratory rate and heart rate and decline in $\mathrm{PaCO}_{2}$ levels with increase in $\mathrm{pH}$ and $\mathrm{PaO}_{2}$ levels in patients successfully managed with NIPPV. However, there was no difference in improvement of clinical and blood gas parameters between the two groups except the rate of decline of $\mathrm{pH}$ at one and four hours and $\mathrm{PaCO}_{2}$ at one hour which was significantly faster in the COPD group. NIPPV failures were significantly higher in ARF due to other causes $(15 / 39)$ than in ARF-COPD $(3 / 24)(p=0.03)$. The mean ICU and hospital stay and the hospital mortality were similar in the two groups. In the multivariate logistic regression model (after adjusting for gender, APACHE II scores and improvement in respiratory rate, $\mathrm{pH}, \mathrm{PaO}_{2}$ and $\mathrm{PaCO}_{2}$ at one hour) only the etiology of ARF, ie, ARF-COPD, was associated with a decreased risk of NIPPV failure (odds ratio 0.23 ; 95\% confidence interval, 0.58-0.9).

Conclusions: NIPPV is more effective in preventing endotracheal intubation in ARF due to COPD than other causes, and the etiology of ARF is an important predictor of NIPPV failure.

Keywords: noninvasive ventilation, noninvasive positive pressure ventilation, acute respiratory failure, chronic obstructive pulmonary disease, CPAP, bilevel positive airway pressure, pneumonia, ALI, ARDS

\section{Introduction}

The first-line treatment of patients with acute respiratory failure (ARF) is mechanical ventilation. Patients with ARF can be ventilated either with positive or negative pressure, invasively or noninvasively. Noninvasive ventilation (NIV) is the provision 
of ventilatory support to the lungs without the use of an endotracheal airway. NIV has revolutionized the management of ARF, and has been applied in diverse forms of ARF (Brochard et al 2002). It not only reduces the need for endotracheal intubation and its associated complications like airway trauma, pneumonia and others but also reduces the complications associated with stay in the intensive care unit (ICU), the length of hospital stay, and mortality in selected group of patients (Brochard 2003; Liesching et al 2003). However, the evidence for the use of NIV remains strongest in patients with hypercapnic ARF due to exacerbations of chronic obstructive pulmonary disease (COPD) and cardiogenic pulmonary edema (Ram et al 2004; Agarwal et al 2005). Positive pressure therapy can be delivered noninvasively by noninvasive positive pressure ventilation (NIPPV) (or bi-level positive airway pressure) and continuous positive airway pressure (CPAP). In NIPPV, two different pressures are used viz. inspiratory positive airway pressure (IPAP) and expiratory positive airway pressure (EPAP), whereas CPAP maintains a constant positive airway pressure throughout the respiratory cycle. Theoretically, NIPPV may confer an advantage over CPAP by reducing the work of breathing during inspiration by providing additional inspiratory pressure. While there is strong evidence to support the use of NIPPV in COPD, the role of NIV in hypoxemic ARF unrelated to CPE is controversial. Two recent meta-analyses did not find any strong evidence to support the role of NIV in acute hypoxemic respiratory failure and acute respiratory distress syndrome respectively (Keenan et al 2004; Agarwal et al 2006).

The application of NIPPV in the management of patients with ARF is not associated with a $100 \%$ success rate. In many patients application of NIV is clearly insufficient as it does not obtain adequate ventilation and eventually endotracheal intubation and invasive mechanical ventilation is required for the management of respiratory failure. Also, some patients will initially benefit from NIPPV (for hours to few days) but will then deteriorate and require intubation. The failure rates of NIPPV can range from $5 \%$ to $50 \%$ in different studies depending on the etiology and severity of ARF (Plant et al 2001; Nava and Ceriana 2004; Confalonieri et al 2005; Phua et al 2005). Failure to identify the patients who are likely to fail NIPPV can cause inappropriate delay in intubation; this can lead to clinical deterioration and increased morbidity and mortality (Nava and Ceriana 2004). Thus, it becomes important to ascertain the factors associated with NIV failure so that we can identify the high-risk subset of patients who are likely to fail a trial of NIV. This subject has been widely researched with abundant data published from the developed world (Soo Hoo et al 1994; Cheung et al 2000; Lightowler and Elliott 2000; Antonelli et al 2001; Azoulay et al 2001; Carlucci et al 2001; Plant et al 2001; Afessa et al 2002; Hess 2004; Nava and Ceriana 2004; Jaber et al 2005; Phua et al 2005; Budweiser et al 2007; Lellouche 2007). However, there is still a paucity of literature from India on NIV despite the fact that this modality of treatment can assume significant relevance in resource constrained setting. In fact, there are only two published original articles investigating the role of NIV from India (Singh et al 2006; George et al 2007). The aim of this study is to describe the effectiveness of NIPPV in ARF due to COPD vs other conditions, and also to describe the factors predicting failure of NIPPV from a respiratory intensive care unit (ICU) in North India.

\section{Patients and methods}

This was a prospective observational study conducted in the respiratory intensive care unit (RICU) of this institute. All patients requiring NIPPV for ARF between July 2001 and December 2002 were enrolled in the study. The study was cleared by the Institute Ethics Committee and written consent was obtained from all patients or the next of kin.

Patients were included in the study if they met the definition of acute respiratory failure defined by the presence of both of the following criteria: (a) clinical signs and symptoms of acute respiratory distress: dyspnea, respiratory rate more than 24 breaths per minute, use of accessory muscles of respiration, presence of paradoxical breathing; and, (b) arterial blood gas $(\mathrm{ABG})$ analysis with $\mathrm{pH}<7.35$ and partial pressure of oxygen in arterial blood $\left(\mathrm{PaO}_{2}\right)$ /fraction of inspired oxygen concentration $\left(\mathrm{FiO}_{2}\right.$ ) ratio less than 200 (or $\mathrm{PaO}_{2}$ less than $60 \mathrm{~mm} \mathrm{Hg}$ ). They were further classified as type 1 or hypoxemic respiratory failure if partial pressure of carbon dioxide in arterial blood $\left(\mathrm{PaCO}_{2}\right)$ was less than $45 \mathrm{~mm} \mathrm{Hg}$; and, type 2 or hypercapnic respiratory failure if $\mathrm{PaCO}_{2}$ was more than or equal to $45 \mathrm{~mm} \mathrm{Hg}$. Patients were excluded from the study if they met any of the following criteria: respiratory arrest, medically unstable condition (hypotension, uncontrolled cardiac ischemia/arrhythmia etc.), inability to protect airway (excess secretions, stuporous or comatose patient), abnormalities which preclude proper fit of the interface (agitated or uncooperative patient, facial trauma or burns, facial surgery or facial anatomical abnormality).

Noninvasive ventilation was administered with the use of portable noninvasive ventilator VPAP II (ResMed, Sydney, Australia). NIPPV was delivered to patients in bed at an angle of $30-45^{\circ}$ and in all patients a full face mask (UltraMirage, Sydney, Australia) was used as an interface for delivery of 
positive pressure. At the outset the patient was started on an IPAP of 8 and EPAP of $4 \mathrm{~cm} \mathrm{H}_{2} \mathrm{O}$. The pressures were gradually adjusted as tolerated based on continuous pulse oximetry (to achieve saturation of peripheral oxygen $\left[\mathrm{SpO}_{2}\right]$ of $90 \%-92 \%$ ), arterial blood gases (at one and four hours and periodically thereafter as clinically indicated), alleviation of patient's dyspnea, decrease in respiratory rate and good patient - ventilator synchrony. Oxygen supplementation was provided through a port in the mask to keep $\mathrm{SpO}_{2}>90 \%$. Air leaks were frequently checked for, and the patient was constantly encouraged and reassured. The duration of NIPPV and the time to stop NIPPV was determined based on clinical judgment and arterial blood gas values.

At admission, the demographic details of patient were recorded which included age, sex, body mass index, etiology of ARF and the presence and absence of associated co-morbid illnesses. The disease severity was calculated using Acute Physiology and Chronic Health Evaluation (APACHE) II scores. We prospectively collected the data for heart rate, respiratory rate, arterial blood gases $\left(\mathrm{pH}, \mathrm{PaO}_{2}, \mathrm{PaCO}_{2}\right)$ at baseline, one and four hours.

The primary outcome was NIPPV failure, defined as the need for endotracheal intubation during the ICU stay due to inability to improve or stabilize gas exchange or dyspnea in one hour or failure to improve mental status within 60 minutes of initiating NIPPV in patients who were lethargic from $\mathrm{CO}_{2}$ retention or agitated from hypoxemia. Ultimately, clinical judgment was applied in the decision to intubate any patient. We also noted the time spent on NIV, the ICU and the hospital length of stay.

Statistical analysis was performed using the statistical package SPSS (version 10; SPSS Inc; Chicago, IL, USA). Results are presented in a descriptive fashion as number (percentage) or means (standard deviation) unless otherwise stated. The differences between means of continuous and categorical variables were analyzed using MannWhitney $U$ and chi-square test respectively. Improvements in clinical (respiratory and heart rate) and arterial blood gas parameters $\left(\mathrm{pH}, \mathrm{PaO}_{2}, \mathrm{PaCO}_{2}\right)$ was analyzed using multiple analysis of variance (MANOVA) with Bonferroni adjustment for multiple comparisons; the within-groups factor was time (zero, one and four hours), and the between-groups factor was the etiology of ARF (COPD vs other causes of ARF). Statistical significance was assumed at a p-value of less than 0.05 . Multivariate logistic regression analysis was performed to derive adjusted odds ratio (AOR) and 95\% confidence intervals (CI) using the following variables: gender, APACHE II scores, change in respiratory rate, $\mathrm{pH}$,
$\mathrm{PaO}_{2}, \mathrm{PaCO}_{2}$ in the first hour after application of NIPPV and etiology (COPD vs other causes of ARF) to analyze the factors predicting failure of NIPPV (ie, requirement of endotracheal intubation).

\section{Results}

During the study period 248 patients were admitted in the RICU, and of these 63 (25.4\%) patients met the inclusion criteria and were initiated on NIPPV. The most common etiology requiring initiation of NIPPV was acute exacerbations of COPD (Table 1) with thirty-seven (58.7\%) patients having evidence of hypercapnic acute respiratory failure. The baseline characteristics of patients included in the study are shown in Table 2. There were 40 male and 23 female patients with a mean (SD) age of 45.7 (16.6) years. Patients with ARF secondary to COPD were older, had higher APACHE II scores, lower respiratory rates, lower $\mathrm{pH}$ and higher $\mathrm{PaCO} 2$ levels compared to other causes of ARF (Table 2).

The serial clinical and arterial blood gas parameters are shown in Table 3. After one hour there was a significant improvement in clinical (decrease in respiratory rate and heart rate) and blood gas (decline in $\mathrm{PaCO}_{2}$ levels with increase in $\mathrm{pH}$ and $\mathrm{PaO}_{2}$ levels) parameters in patients successfully managed with NIPPV. At four hours, there was a decrement in respiratory rate, heart rate and increase in $\mathrm{pH}$ but no difference in $\mathrm{PaO}_{2}$ and $\mathrm{PaCO}_{2}$ levels. However, when the two groups (ARF - COPD vs others) were compared there was no difference in improvement of clinical and blood gas parameters between the two groups except the rate of decline of $\mathrm{pH}$ at one and four hours and $\mathrm{PaCO}_{2}$ at one hour which was significantly faster in the COPD group (Table 3$)$. The mean (SD) IPAP/EPAP administered was $17.6(2.8) / 8.4(1.7) \mathrm{cm}$ $\mathrm{H}_{2} \mathrm{O}$ and was administered for a mean duration of 19.6 hours.

Table I Etiology of acute respiratory failure $(n=63)$

\begin{tabular}{ll}
\hline Etiology & Number (\%) \\
\hline Acute exacerbations of COPD & $24(38.1)$ \\
Others & $15(23.8)$ \\
$\quad$ Pneumonia & $9(14.3)$ \\
Sepsis-related lung injury & $6(9.5)$ \\
Asthma & $6(9.5)$ \\
Acute worsening of obstructive & \\
sleep apnea & $3(4.8)$ \\
Post-extubation respiratory failure & 37 \\
Hypercapnic & 26 \\
Hypoxemic &
\end{tabular}

Note: Numbers in parenthesis are percentages until otherwise stated. Abbreviation: COPD, chronic obstructive pulmonary disease. 
Table 2 Baseline characteristics of patients with acute respiratory failure stratified by etiology

\begin{tabular}{|c|c|c|c|c|}
\hline Variable & COPD $(n=24)$ & Others $(n=39)$ & Total $(n=63)$ & $P$ value \\
\hline Age (years) & $56(11.8)$ & $39.3(16.1)$ & $45.7(16.6)$ & 0.0001 \\
\hline Female gender, No. (\%) & $9(37.5)$ & 14 (35.9) & $23(36.5)$ & 0.9 \\
\hline BMI $\left(\mathrm{kg} / \mathrm{m}^{2}\right)$ & $21.7(4.7)$ & $25.4(6.9)$ & $24(6.4)$ & 0.02 \\
\hline $\begin{array}{l}\text { Presence of other co-morbid } \\
\text { illness, No. (\%) }\end{array}$ & $18(75)$ & $27(69.2)$ & 45 (7I.4) & 0.08 \\
\hline APACHE II scores & $21.7(4.8)$ & I6.7 (4.8) & $18.6(5.4)$ & 0.0001 \\
\hline Respiratory rate (breaths/min) & $34.1(7.4)$ & $38.2(7.8)$ & $36.7(7.9)$ & 0.04 \\
\hline Heart rate (beats/min) & $116.8(16.9)$ & II $4.4(19.3)$ & II $5.3(18.3)$ & 0.35 \\
\hline $\mathrm{pH}$ & $7.27(0.07)$ & $7.36(0.12)$ & $7.33(0.11)$ & 0.002 \\
\hline $\mathrm{PaO}_{2} / \mathrm{FiO}_{2}$ & $198.9(33)$ & $149(58.3)$ & I68.2 (55.4) & 0.001 \\
\hline $\mathrm{PaCO}_{2}(\mathrm{~mm} \mathrm{Hg})$ & $73.1(24.3)$ & $43.3(16.1)$ & $54.6(24.3)$ & 0.0001 \\
\hline
\end{tabular}

Abbreviations: $\mathrm{BMI}$, body mass index; $\mathrm{COPD}$, chronic obstructive pulmonary disease; $\mathrm{FiO}_{2}$, fraction of inspired oxygen concentration; PaCO ${ }_{2}$, partial pressure of carbon dioxide in arterial blood; $\mathrm{PaO}_{2}$, partial pressure of oxygen in the arterial blood.

The duration of ventilation (or the time to resolution of ARF) was not significantly different in COPD when compared to other causes of ARF in patients successfully managed with NIPPV (Table 4).

Overall NIPPV was successful in $71.4 \%$ with three out of $24(12.5 \%)$ patients in the COPD group and 15 out of 39 (38.5\%; pneumonia/ARDS, 12; asthma, one; post-extubation respiratory failure, two) patients in ARF due to other causes group requiring endotracheal intubation and invasive ventilation respectively, and was statistically significant $(p=0.03)$. The odds of NIPPV failure was 4.38 (95\% confidence intervals [CI] 1.01-26.24) in ARF due to other causes compared to COPD-ARF. All the three patients requiring invasive ventilation in the COPD-ARF group died whereas seven patients in the ARF-other causes group died to multiple organ dysfunction. The ICU (mean [SD], 2.4 [1.1] in COPD-ARF and 3.4 [3] in ARF-other causes) and hospital stay (mean [SD], 3.5 [1.6] in COPD-ARF and 4 [3.1] in ARF-other causes) was found to be similar in the two groups.
Multivariate logistic regression analysis was performed to assess the factors predicting endotracheal intubation in patients ventilated with NIPPV (Table 4). In the univariate analysis, female gender, improvement in $\mathrm{pH}$ at one hour and the etiology of ARF were associated with favorable outcome (Table 5). However, in the multivariate model (Table 5), after adjustment (for gender, APACHE II scores and improvement in respiratory rate, $\mathrm{pH}, \mathrm{PaO}_{2}, \mathrm{PaCO}_{2}$ at one hour) only the etiology which necessitated NIPPV ie, ARF secondary to COPD was associated with a successful outcome (odds ratio [OR] 0.23; 95\% CI, 0.58-0.9).

\section{Discussion}

The results of this study show that NIPPV can be utilized as an effective modality in the management of ARF due to diverse etiologies. However, the success rate of NIPPV was significantly higher for ARF due to COPD than other causes of ARF. In fact, in the multivariate analysis, the etiology of ARF necessitating NIV was the only significant predictor

Table 3 Serial clinical and arterial blood gas parameters during the ICU course of the two groups receiving NIPPV

\begin{tabular}{|c|c|c|c|c|c|c|}
\hline & \multicolumn{3}{|l|}{ ARF-COPD } & \multicolumn{3}{|l|}{ ARF-others } \\
\hline & 0 hour & I hour & 4 hour & 0 hour & I hour & 4 hour \\
\hline RR & 34.1 (7.4) & $31.7(5.3)^{\mathrm{a}}$ & $29.1(3.5)^{b}$ & $38.2(7.8)$ & $33.7(6.4)^{\mathrm{a}}$ & $29.4(4.3)^{b}$ \\
\hline$H R$ & II $6.8(16.9)$ & $109.2(11.7)^{\mathrm{a}}$ & $101(10.2)^{b}$ & II4.4 (19.3) & $107.7(17.7)^{\mathrm{a}}$ & $97.3(11.9)^{b}$ \\
\hline $\mathrm{pH}$ & $7.27(0.07)$ & $7.337(0.07)^{\mathrm{a}}$ & $7.378(0.07)^{\mathrm{b}}$ & $7.36(0.12)$ & $7.376(0.09)^{\mathrm{a}, \mathrm{c}}$ & $7.405(0.06)^{b, d}$ \\
\hline $\mathrm{PaO}_{2}$ & $55.6(16.1)$ & $61.5(9.7)^{\mathrm{a}}$ & $64.2(7.9)$ & $52.9(7.38)$ & $64.1(13.4)^{\mathrm{a}}$ & $70.4(10.8)$ \\
\hline $\mathrm{PaCO}_{2}$ & $73.1(24.3)$ & $56.4(16.5)^{\mathrm{a}}$ & $53.6(14.9)$ & $43.3(16.1)$ & $40.4(14.2)^{\mathrm{a}, \mathrm{c}}$ & 43.1 (13.5) \\
\hline
\end{tabular}

Notes: ${ }^{2}$ value at I hour significantly different from that at baseline within the groups; ${ }^{b}$ value at 4 hour significantly different from that at I hour within the groups; ${ }^{c}$ value at I hour significantly different from that at baseline between the two groups; ${ }^{\mathrm{d}}$ value at 4 hour significantly different from that at I hour between the two groups. A p-value less than 0.05 were taken as significant. The differences between the means was analyzed using MANOVA with Bonferroni adjustment for multiple comparisons; the within-groups factor was time ( 0,1 and 4 hours), and the between-groups factor was the etiology of ARF (COPD vs other causes of ARF).

Abbreviations: ARF, acute respiratory failure; COPD, chronic obstructive pulmonary disease; HR, heart rate; ICU, intensive care unit; NIPPV, noninvasive positive pressure ventilation; $\mathrm{PaCO}_{2}$, partial pressure of carbon dioxide in arterial blood; $\mathrm{PaO}_{2}$, partial pressure of oxygen in the arterial blood; $\mathrm{RR}$, respiratory rate. 
Table 4 Outcome parameters during the ICU course of the two groups receiving NIPPV

\begin{tabular}{lllll}
\hline Variable & COPD $(\mathbf{n}=\mathbf{2 4})$ & Others $(\mathbf{n}=\mathbf{3 9})$ & Total $(\mathbf{n}=\mathbf{6 3})$ & P value \\
\hline Duration of NIPPV** & $15.8(15.5)$ & $21.9(19.9)$ & $19.6(18.5)$ & 0.2 \\
Successful Outcome & $21(87.5)$ & $24(61.5)$ & $45(71.4)$ & $2.8(2.1)$ \\
Duration of ICU stay & $2.4(1.1)$ & $3.4(3)$ & $3.7(2.3)$ & $0.03 *$ \\
Duration of hospital stay & $3.5(1.6)$ & $4(3.1)$ & $10(15.9)$ & 0.57 \\
Mortality & $3(12.5)$ & $7(17.9)$ & 10.66 \\
\hline
\end{tabular}

Notes: "statistically significant; ;

Abbreviations: COPD, chronic obstructive pulmonary disease; ICU, intensive care unit; NIPPV, noninvasive positive pressure ventilation.

of successful outcome. Even the severity of the illness at admission in the ICU as assessed by the APACHE II scores was not a significant predictor of failure in our study. The success rate of NIPPV was $87.5 \%$ for ARF due to COPD and $61.5 \%$ for ARF due to other causes which are similar to reintubation rates described elsewhere both from India (Singh et al 2006; George et al 2007) and the EuropeanAmerican countries (Antonelli et al 2001; Afessa et al 2002; Phua et al 2005). There is little doubt on the efficacy of NIV in ARF due to COPD (Ram et al 2004) and cardiogenic pulmonary edema (Agarwal et al 2005). The role of NIV in other etiologies of ARF such as pneumonia, asthma, ARDS is controversial, and controlled trials for the use of NIV in acute exacerbations of obstructive sleep apnea, bronchiectasis and diffuse parenchymal lung diseases are lacking. This fact was also reflected in this study with almost $40 \%$ failure rate with NIPPV in ARF due to other etiologies.

In general, the factors predicting success/failure with NIPPV in hypercapnic respiratory failure include $\mathrm{pH}$ at admission, $\mathrm{pH}$ after one hour of NIPPV trial and severity of underlying illness (Chevrolet et al 1991; Ambrosino et al 1995; Meduri et al 1996; Wood et al 1998; Plant et al 2000, 2001; Carlucci et al 2003; Girault et al 2003; Nava and Ceriana 2004; Carratù et al 2005). In patients with hypoxemic respiratory failure the factors predicting the need for endotracheal intubation include age, severity of underlying illness, baseline $\mathrm{PaO}_{2} / \mathrm{FiO}_{2}$ scores and the presence or absence of pneumonia/ARDS (Antonelli et al 2001; Nava and Ceriana 2004; Schettino et al 2008).

One important predictor of NIV failure has been the severity of the underlying illness as assessed by the APACHE II scores or similar scoring systems (Antonelli et al 2001; Phua et al 2005) although some studies have failed to demonstrate this observation (Benhamou et al 1992; Meduri et al 1996; Antón et al 2000; Lightowler and Elliott 2000; Moretti et al 2000). Even in this study, the APACHE II scores did not predict NIPPV failure. The probable reason for this is the difference in the baseline characteristics of the study population in the two groups of ARF. Patients with ARF due to COPD were significantly older when compared to other causes of ARF (mean age, 56 years in COPD group versus 39 years in the others; $p<0.0001$ ). This difference led to a higher APACHE II scores in the COPD population compared to the other group (mean APACHE II scores, 21.7 in the COPD group versus 16.7 in the other group; $\mathrm{p}<0.0001)$.

There was a significant improvement in clinical and blood gas values with the use of NIPPV in both the groups. However, the baseline clinical (heart rate, respiratory rate) and arterial blood gas parameters, and their serial values did

Table 5 Factors predicting outcome of NIPPV: univariate and multivariate analysis

\begin{tabular}{|c|c|c|c|c|}
\hline Variable & Success $(n=45)$ & Failure $(n=18)$ & Crude OR $(95 \% \mathrm{Cl})$ & Adjusted OR $(95 \% \mathrm{Cl})$ \\
\hline Female gender, No & 20 & 3 & $0.25(0.06-0.25)^{*}$ & $0.24(0.05-1.1 I)$ \\
\hline APACHE II scores & $19.1(5.6)$ & $17.5(4.8)$ & $0.95(0.86-1.05)$ & $1.06(0.91-1.24)$ \\
\hline Delta $R_{(0-1 ~ h r)}$ & $-4.3(6.7)$ & $-2.1(8.3)$ & $1.05(0.96-1.14)$ & $1.03(0.94-1.14)$ \\
\hline Delta $\mathrm{pH}_{(0-1 \mathrm{hr})}$ & $0.04(0.06)$ & $0.005(0.06)$ & $0(0-0.32)^{*}$ & $0(0-18.3)$ \\
\hline Delta $\mathrm{PaO}_{2(0-1 \mathrm{hr})}$ & $10.7(9.5)$ & $6.4(9.2)$ & $0.99(0.95-1.02)$ & $0.96(0.9-1.01)$ \\
\hline Delta $\mathrm{PaCO}_{2(0-1 \mathrm{hr})}$ & $5(19.8)$ & I3.4(I8.6) & $1.02(0.99-1.05)$ & I (0.96-I.04) \\
\hline Etiology (COPD: Others) & $21: 24$ & $3: 15$ & $0.23(0.58-0.9)^{*}$ & $0.12(0.02-0.95)^{*}$ \\
\hline
\end{tabular}

Note: ${ }^{*} \mathrm{P}<0.05$.

Abbreviations: (0-I), baseline minus one hour; APACHE, acute physiology and chronic health evaluation; Cl, confidence interval; COPD, chronic obstructive pulmonary disease; $\mathrm{OR}$, odds ratio; $\mathrm{PaCO}_{2}$, partial pressure of carbon dioxide in arterial blood; $\mathrm{PaO}_{2}$, partial pressure of oxygen in the arterial blood; $\mathrm{RR}$, respiratory rate. 
not predict successful outcome in this study. The reason for this is the fact that majority of the failures have occurred in the ARF due to other causes group wherein the failure rate of NIPPV was very high. In this group (majority were patients with pneumonia/ARDS), a transient improvement in the clinical and blood gas parameter does occur with NIPPV but the underlying process such as sepsis or pneumonia is not affected by NIPPV; and improvement with antibiotics and other supportive measures takes at least 24-48 hours which can cause late NIPPV failure despite an improvement in the early hours (Moretti et al 2000; Antonelli et al 2001; Carlucci et al 2001; Schettino et al 2008). This point is further reflected in a recent study in which the failure rate of NIPPV for acute hypoxemic respiratory failure was as high as 60\% (Schettino et al 2008). Even in our study, the failure rate of NIPPV was $50 \%$ in the pneumonia/ARDS group of patients. Also there are a subset of patients who initially seem to respond to NIPPV but then fail to improve with NIV and this cohort of patients are termed as "late NIV failures" (Moretti et al 2000; Carratù et al 2005). In patients with late NIPPV failures, the improvement in clinical parameters and arterial blood gases does not predict successful outcome with NIPPV.

There is also a great importance of international comparison of ICU data. However, there is a paucity of data from India on the use of NIPPV in ARF. In fact, only two prospective studies have been published which have investigated the use of NIPPV in patients with ARF of varied causes (Singh et al 2006; George et al 2007). However, both the studies have certain limitations. One study had disproportionate number of patients with hypercapnic respiratory failure (36 hypercapnic ARF and 4 hypoxemic ARF) (George et al 2007). Although both the studies suggested certain factors that predict the success or failure of NIPPV, neither of the two studies had used multivariate analysis for predicting the outcome of NIPPV which decreases the robustness and applicability of their results. Although there are numerous studies determining the factors predicting failure of NIPPV in acute respiratory failure due to COPD and other causes, there is none from the Indian subcontinent and this study provides the Indian perspective on this issue.

The strength of this study is the prospective nature of the study and the fact that robust statistical methods have been used for analysis of the data so that the results can be interpreted with confidence. We have used MANOVA for repeated measures which can test more complex hypotheses and is thus more powerful than using multiple t-tests. Similarly we have used multivariate analysis for assessing the risk factors affecting NIPPV failure; this statistical method assumes significance only after correcting for other covariates removing the effect of confounding.

Finally, our study is also not without limitations. The major limitations of our study include the relatively small number of patients (although it is the largest number of patient data published from India on NIV). Thus many of the conclusions regarding risk factors in our study have limitations because of the small numbers of patients in each group; the small data set does not allow for a valid assessment, of whether some of these conditions in the study population may or may not be a contributing factor for success or failure of NIPPV. Currently, patients who require NIPPV are managed with critical care ventilators which have facilities for better oxygen delivery (due to the presence of oxygen blender) and better patient monitoring facilities (Liesching et al 2003). However, when this study was performed, due to resource constraints, the RICU possessed only a domiciliary noninvasive ventilator and was thus used in this study.

As the demand for NIV increases, its use should be limited to settings in which there is the strongest evidence of benefit from high quality clinical trials such as in acute exacerbations of COPD, cardiogenic pulmonary edema and in patients at high risk of post-extubation respiratory failure (Ram et al 2004; Agarwal et al 2005, 2007). And, conversely, the use of NIV in septic patients and others with ill-defined acute respiratory failure should be curtailed (Antonelli et al 2001; Agarwal et al 2006). The results of our study are similar to many other studies which suggest that NIPPV is likely to have limited applicability in ARF due to causes other than COPD and acute cardiogenic pulmonary edema (Demoule et al 2006; Schettino et al 2008).

In conclusion, this study demonstrates that NIPPV is an effective modality in preventing endotracheal intubation in ARF due to COPD but has limited applicability in ARF secondary to other causes. Within limitations of the current study, the study suggests that it is the etiology of ARF which is the most important predictor of NIPPV failure.

\section{Disclosure}

The authors declare no conflicts of interest in this work.

\section{References}

Afessa B, Morales IJ, Scanlon PD, et al. 2002. Prognostic factors, clinical course, and hospital outcome of patients with chronic obstructive pulmonary disease admitted to an intensive care unit for acute respiratory failure. Crit Care Med, 30:1610-5.

Agarwal R, Aggarwal AN, Gupta D, et al. 2005. Non-invasive ventilation in acute cardiogenic pulmonary oedema. Postgrad Med J, 81:637-43.

Agarwal R, Aggarwal AN, Gupta D, et al. 2007. Role of noninvasive positive-pressure ventilation in postextubation respiratory failure: a meta-analysis. Respir Care, 52:1472-9. 
Agarwal R, Reddy C, Aggarwal AN, et al. 2006. Is there a role for noninvasive ventilation in acute respiratory distress syndrome? A metaanalysis. Respir Med, 100:2235-8.

Ambrosino N, Foglio K, Rubini F, et al. 1995. Non-invasive mechanical ventilation in acute respiratory failure due to chronic obstructive pulmonary disease: correlates for success. Thorax, 50:755-7.

Antón A, Güell R, Gómez J, et al. 2000. Predicting the result of noninvasive ventilation in severe acute exacerbations of patients with chronic airflow limitation. Chest, 117:828-33.

Antonelli M, Conti G, Moro ML, et al. 2001. Predictors of failure of noninvasive positive pressure ventilation in patients with acute hypoxemic respiratory failure: a multi-center study. Intensive Care Med, 27:1718-28.

Azoulay E, Alberti C, Bornstain C, et al. 2001. Improved survival in cancer patients requiring mechanical ventilatory support: impact of noninvasive mechanical ventilatory support. Crit Care Med, 29:519-25.

Benhamou D, Girault C, Faure C, et al. 1992. Nasal mask ventilation in acute respiratory failure. Experience in elderly patients. Chest, 102:912-7.

Brochard L. 2003. Mechanical ventilation: invasive versus noninvasive. Eur Respir J, 23(Suppl 47):S31-7.

Brochard L, Mancebo J and Elliott MW. 2002. Noninvasive ventilation for acute respiratory failure. Eur Respir J, 19:712-21.

Budweiser S, Jorres RA, Riedl T, et al. 2007. Predictors of survival in COPD patients with chronic hypercapnic respiratory failure receiving noninvasive home ventilation. Chest, 131:1650-8.

Carlucci A, Delmastro M, Rubini F, et al. 2003. Changes in the practice of non-invasive ventilation in treating COPD patients over 8 years. Intensive Care Med, 29:419-25.

Carlucci A, Richard JC, Wysocki M, et al. 2001. Noninvasive versus conventional mechanical ventilation. An epidemiologic survey. Am J Respir Crit Care Med, 163:874-80.

Carratù P, Bonfitto P, Dragonieri S, et al. 2005. Early and late failure of noninvasive ventilation in chronic obstructive pulmonary disease with acute exacerbation. Eur J Clin Invest, 35:404-9.

Cheung MT, Yam LY, Lau CW, et al. 2000. Use of non-invasive positivepressure ventilation for acute respiratory failure: prospective study. Hong Kong Med J, 6:361-7.

Chevrolet JC, Jolliet P, Abajo B, et al. 1991. Nasal positive pressure ventilation in patients with acute respiratory failure. Difficult and timeconsuming procedure for nurses. Chest, 100:775-82.

Confalonieri M, Garuti G, Cattaruzza MS, et al. 2005. A chart of failure risk for noninvasive ventilation in patients with COPD exacerbation. Eur Respir J, 25:348-55.

Demoule A, Girou E, Richard JC, et al. 2006. Increased use of noninvasive ventilation in French intensive care units. Intensive Care Med, 32:1747-55.

George IA, John G, John P, et al. 2007. An evaluation of the role of noninvasive positive pressure ventilation in the management of acute respiratory failure in a developing country. Indian J Med Sci, 61:495-504.

Girault C, Briel A, Hellot MF, et al. 2003. Noninvasive mechanical ventilation in clinical practice: a 2-year experience in a medical intensive care unit. Crit Care Med, 31:552-9.
Hess DR. 2004. The evidence for noninvasive positive-pressure ventilation in the care of patients in acute respiratory failure: a systematic review of the literature. Respir Care, 49:810-29.

Jaber S, Delay JM, Chanques G, et al. 2005. Outcomes of patients with acute respiratory failure after abdominal surgery treated with noninvasive positive pressure ventilation. Chest, 128:2688-95.

Keenan SP, Sinuff T, Cook DJ, et al. 2004. Does noninvasive positive pressure ventilation improve outcome in acute hypoxemic respiratory failure? A systematic review. Crit Care Med, 32:2516-23.

Lellouche F. 2007. Noninvasive ventilation in patients with hypoxemic acute respiratory failure. Curr Opin Crit Care, 13:12-9.

Liesching T, Kwok H, Hill NS. 2003. Acute applications of noninvasive positive pressure ventilation. Chest, 124:699-713.

Lightowler JV, Elliott MW. 2000. Predicting the outcome from NIV for acute exacerbations of COPD. Thorax, 55:815-6.

Meduri GU, Turner RE, Abou-Shala N, et al. 1996. Noninvasive positive pressure ventilation via face mask. First-line intervention in patients with acute hypercapnic and hypoxemic respiratory failure. Chest, 109:179-93.

Moretti M, Cilione C, Tampieri A, et al. 2000. Incidence and causes of non-invasive mechanical ventilation failure after initial success. Thorax, 55:819-25.

Nava S, Ceriana P. 2004. Causes of failure of noninvasive mechanical ventilation. Respir Care, 49:295-303.

Phua J, Kong K, Lee KH, et al. 2005. Noninvasive ventilation in hypercapnic acute respiratory failure due to chronic obstructive pulmonary disease vs. other conditions: effectiveness and predictors of failure. Intensive Care Med, 31:533-9.

Plant PK, Owen JL, Elliott MW. 2000. Early use of non-invasive ventilation for acute exacerbations of chronic obstructive pulmonary disease on general respiratory wards: a multicentre randomised controlled trial. Lancet, 355:1931-5.

Plant PK, Owen JL, Elliott MW. 2001. Non-invasive ventilation in acute exacerbations of chronic obstructive pulmonary disease: long term survival and predictors of in-hospital outcome. Thorax, 56:708-12.

Ram FSF, Picot J, Lightowler J, et al. 2004. Non-invasive positive pressure ventilation for treatment of respiratory failure due to exacerbations of chronic obstructive pulmonary disease. Cochrane Database Syst Rev, 3:CD004104.

Schettino G, Altobelli N, Kacmarek RM. 2008. Noninvasive positivepressure ventilation in acute respiratory failure outside clinical trials: experience at the Massachusetts General Hospital. Crit Care Med, 36:441-7.

Singh VK, Khanna P, Rao BK, et al. 2006. Outcome predictors for non-invasive positive pressure ventilation in acute respiratory failure. $J$ Assoc Physicians India, 54:361-5.

Soo Hoo GW, Santiago S, Williams AJ. 1994. Nasal mechanical ventilation for hypercapnic respiratory failure in chronic obstructive pulmonary disease: determinants of success and failure. Crit Care Med, 22:1253-61.

Wood KA, Lewis L, Von Harz B, et al. 1998. The use of noninvasive positive pressure ventilation in the emergency department: results of a randomized clinical trial. Chest, 113:1339-46. 
